\title{
Characteristics of Surface Tension on First Edible Oil and Frying the Mixed with Candles by Using Torsion Dynamometer
}

\author{
Dwi Windarti", M. Faruq Najib, Frida Agung Rakhmadi \\ Physics Department, Faculty of Science and Technology, UIN SunanKalijaga \\ Jl. Marsda Adisucipto No. 1 Yogyakarta 55281, Indonesia. Tel. + 62-274-540971, Fax. + 62-274-519739 \\ Email: dwiwindarti368@gmail.com
}

\begin{abstract}
Cooking oil pure with the content that has been determined according to the needs that require measurement data minimum and the measurement of the maximum permissibility of the oil it consumed, and the content contained in the oil should have a standard that had been determined by laboratory results that do not interfere with the system of the body when consumed. However, when the pure cooking oil that has been supplemented with other substances or other material that would change the sound into different standard. By way of meeting the data compare surface on pure cooking oil and cooking oil wax mixture. So with this study we can know the difference in surface tension characteristics with Torsion Dynamometer that the elections were not arbitrary and cooking oil consumed well and healthy.
\end{abstract}

Keywords: Candle, Cooking oil, Level meeting, Surface tension

\section{INTRODUCTION}

We often encounter it in daily life, namely fried or fried dishes. In the frying process it definitely needs cooking oil. Cooking oil comes from raw coconut, copra, palm oil, soybeans, corn kernels and others. Cooking oil is a purified vegetable oil and can be used as food ingredients. Where is this cooking oil that meets health standards so that it can be consumed without causing negative effects on the health of its consumption. Therefore, a quality standard of cooking oil is needed. The standard of cooking oil in Indonesia refers to the National Standardization Agency although it still experiences expansion based on the level of quality degradation such as expiration, rancid odor, and the use of pure cooking oil that will repeatedly change the compounds in cooking oil itself, and there are standards the minimum amount of pure cooking oil is how many times the frying is $2 \mathrm{x}$ frying and some are using other ingredients as a mixture of pure cooking oil such as wax, plastic, used oil and other ingredients. In this case pure cooking oil compounds that meet good standards have changed due to the addition of chemicals. This will have an effect on the results of frying and potentially disrupt the immune system in its consumption.

The use of wax as a mixture of cooking oil is carcinogenic which triggers cancer. Candles contain 20 poisons such as trichloroethane, acetone, xylene, phenol, cresol, and chlorobenzene. Usually manufacture of candles is with paraffin which is commonly known as petroleum. Paraffin is a saturated hydrocarbon with an open chain and is an alkane compound, the common name for paraffin is carbon alkane with the formula $\mathrm{CnH} 2 \mathrm{n}+2$, wax refers to solid objects with $\mathrm{n}=20-40$. With very large atomic components and to separate the components, multilevel distillation is carried out with a boiling point of $38^{\circ} \mathrm{C}$ $205^{\circ} \mathrm{C}$. Can also be obtained from the crystallization process after the distillation process is carried out.

When cooking oil is heated with a range of $200^{\circ} \mathrm{C}$ $250^{\circ} \mathrm{C}$, the quality of cooking oil will experience degradation which can lead to poisoning and other things. Because cooking oil which has more heating, it will cause the compounds in cooking oil to be carcinogenic. And if cooking oil mixed with other ingredients such as wax, will cause a worse impact than using only cooking oil which is heated more than the standard temperature.

\section{MATERIALS AND METHODS}

\section{Tools and Materials}

The ingredients that need to be prepared are two different oil samples. One sample of pure cooking oil and one sample of cooking oil that has been mixed with wax. The tool used in data retrieval is called the Torsion Dynamometer.

In this study distinguish between pure fried oil and cooking oil that has been mixed with wax which uses the measurement results of the surface tension of pure cooking oil and which is mixed with wax. With a comparison of cooking oil and wax which is $2 / 4$ of 
pure cooking oil. With a blend of pure cooking oil and cooking oil mixed with wax.

By using the de-Nouy ring method, which measures the aging stress of a liquid, by comparing two liquids, the force required to release the ring that is immersed in a liquid is proportional to the surface tension or voltage of the interface. The force needed to release the ring in the liquid is given by a torque wire expressed by dyne. This method can be more accurate than other methods.

\section{Data Processing}

The data processing method above is to determine the amount of surface tension using the equation,

$$
\gamma=\frac{F_{n}}{d}
$$

With Fn is the variation force and $d$ is the ring diameter $(19 \mathrm{~mm})$. While the average value of surface tension can be obtained by the equation,

$$
\bar{\gamma}=\frac{\sum \frac{F_{n}}{d}}{n}
$$

After obtaining the magnitude of the average surface tension, proceed with determining the errata of the experiment using the equation

$$
\Delta \gamma_{n}=\mid \gamma_{n}-\bar{Y}
$$

With $\Delta y_{n}$ is error from the data surface tension. then the average value of surface tension errata can be obtained by the equation

$$
\overline{\Delta y}=\frac{\sum\left|\gamma_{n}-\bar{\gamma}\right|}{n}
$$

\section{RESULTS AND DISCUSSION}

\section{Data Table}

The results of data are shown in (Table 1).

Table 1. The results of data.

\begin{tabular}{ll}
\hline F Pure Cooking Oil $(\mathbf{N})$ & F Cooking Oil Candles $(\mathbf{N})$ \\
\hline 3,7 & 5,1 \\
3,7 & 5,1 \\
3,7 & 5,2 \\
\hline
\end{tabular}

Analysis of the data from this study was obtained in cooking oil candles, mass meetings that play a role in the magnitude of surface tension. Cooking oil candles which is the oil produced from the process of heating oil with a candle will have a greater mass density. Based on the results of the study, the data contained in (table 1) proved that the surface tension of cooking oil candle was greater than that of pure cooking oil. This is consistent with the theory that the amount of surface tension is influenced by several factors, such as type of liquid, temperature, pressure, density, solute concentration, and density.

From the results of the research data showed samples of cooking oil candle and pure cooking oil did not intersect, where the samples of saturated cooking oil were in the range of 5.1 while pure oil samples were in the range of 3.7. The data can be clearly distinguished the value of the surface tension. Therefore, the data can be used as a basis for the detection system.

\section{CONCLUSIONS}

The result is proved that the surface tension of the cooking oil candle was greater than that of pure cooking oil. This is consistent with the theory that the amount of surface tension is influenced by several factors, such as type of liquid, temperature, pressure, density, solute concentration, and density. The data can be clearly distinguished the value of the surface tension. Therefore, the data can be used as a basis for the detection system.

\section{REFERENCES}

Baskara Soca. 2016. Pengembangan Hidung Elektronik untuk Klasifikasi Mutu Minyak Goreng dengan Metode Principal Component Analysis. IJEIS Vol.6, No.2, : 221-230.

Mangidi, Alfahru. 2015. Laporan Praktikum Kimia Fisik II Percobaan II Penentuan Tegangan Permukaan Cairan Dengan Metode Rambat Kapiler. Universitas Halu Oleo Kendari. 